\title{
Diurnal and seasonal fluctuations in the bark respiration of standing Quercus acutissima trees in Nakaizu, Japan
}

\author{
Y. Kakubari \\ Laboratory of Silviculture, University of Shizuoka, Shizuoka, Japan
}

\section{Introduction}

To compare annual carbon balances among different types of forest exosystems or to study the relationship between photosynthetic production and tree growth, the amount of carbon fixed in photosynthesis and the respiratory loss by woody organs must be known approximately. The amount of information about bark respiration in field studies of woody organs of trees is especially limited. In situ measurements on stem respiration rates in trees have been made by Johansson (1933), Negisi (1975), Linder and Troeng (1981), Havranek (1985) and
Kakubari 1988). As a first step, the diurnal and seasonal fluctuations in bark respiration from the stem were measured in standing trees of red oak (Quercus acutissima) in Nakaizu, Shizuoka Pref., Japan.

\section{Materials and Methods}

The measurements of bark respiration were performed from March 1986 to May 1987 in a 19 yr old coppice stand, felled 3 times before, in Nakaizu ( $\mathrm{N} 34^{\circ} 58^{\prime}$, E $139^{\circ} 1^{\prime}$, altitude $320 \mathrm{~m}$ ), about $95 \mathrm{~km}$ northeast of Shizuoka. The general climate is characterized by abundant rainfall (approximately $3700 \mathrm{~mm}$ annually), and the

Table I. General structure and location of bark respiration chambers.

\begin{tabular}{|c|c|c|c|c|c|c|}
\hline \multicolumn{3}{|c|}{ Sample tree } & \multicolumn{4}{|c|}{ Respiration chambers } \\
\hline & $D B H(\mathrm{~cm})$ & $H(m)$ & No. & $H(m)$ & Diam. $(\mathrm{cm})$ & Vol. $(m /)$ \\
\hline \multirow[t]{2}{*}{$\mathrm{d}, *$} & 17.3 & 14.5 & 1 & 6.4 & 11.7 & 1057 \\
\hline & & & 2 & 0.4 & 19.2 & 1079 \\
\hline \multirow{5}{*}{ d, o } & 17.6 & 14.2 & 3 & 12.4 & 3.5 & 227 \\
\hline & & & 4 & 9.2 & 7.8 & 699 \\
\hline & & & 5 & 6.4 & 10.6 & 1022 \\
\hline & & & 6 & 4.0 & 14.3 & 1418 \\
\hline & & & 7 & 0.4 & 20.8 & 1401 \\
\hline$S, 0$ & 11.8 & 12.0 & 8 & 0.4 & 13.0 & 1408 \\
\hline
\end{tabular}


annual average air temperature is $13.8^{\circ} \mathrm{C}$. Bark respiration was measured in 8 parts of stem bark at different heights of dominant (d) and suppressed (s) trees, located at the edge (o) and within $\left({ }^{*}\right)$ the stand (Table I).

The respiration chambers were enclosed with plates of stainless-steel forming cylinders. Air was circulated over the enclosed bark surface at a flow rate of $800-3000 \mathrm{ml} / \mathrm{min}$ through inlet and outlet vinyl tubes attached to the respiration chamber. The xylem temperature was measured with an iron-constantan thermocouple inserted into the inner layer of the bark. The bark respiration and air, xylem and soil temperatures were monitored continuously with a measuring system, connected with an interface board to an 1/O processing unit and infrared gas analyzer (Kakubari, 1988).

\section{Results and Discussion}

Seasonal fluctuations in bark respiration rates in relationship to xylem temperature

In Fig. 1, bark respiration rates measured throughout different seasons are compared with seasonal fluctuations of xylem temperature. Bark respiration rates were at low levels during the spring, autumn and winter, and at high levels from June to August, except for rainy and cold days during the monsoon season. The decrease in respiration rate during the dormant season and its increase during the growing season have been observed in many forest tree species. The increase of respiration rates is connected with the fluctuations of xylem temperatures and diameter growth (Linder and Troeng, 1981; Havranek, 1985).

Diurnal fluctuations in stem bark respiration as related to temperature changes

The diurnal fluctuations of stem bark respiration at $0.4,6.4$ and $12.4 \mathrm{~m}$ at the edge of the stand on 30 July 1986 are shown in Fig. 2 together with photosynthetically active radiation, xylem and air temperatures. The daily course of bark respiration was closely dependent upon xylem temperature changes throughout the day. In the stem near the ground, the xylem temperature was constant at any time of day because of the cooling effect of the sap flow, corresponding to the soil temperature. With increasing heights, xylem temperature rose quicker during the day, and the difference between the daily maximum and minimum values of respiration rates in the upper pant of the stem was greater than that of the lower part of the same stem. Between $600 \mathrm{~h}$ and $1800 \mathrm{~h}$ on July 30 at $0.4 \mathrm{~m}$, the respiration rates at the edge of the stand underwent a daytime depression. The depression was more remarkable in lower parts of the stem and on fine days during the growing season. On cloudy and rainy days, the depression

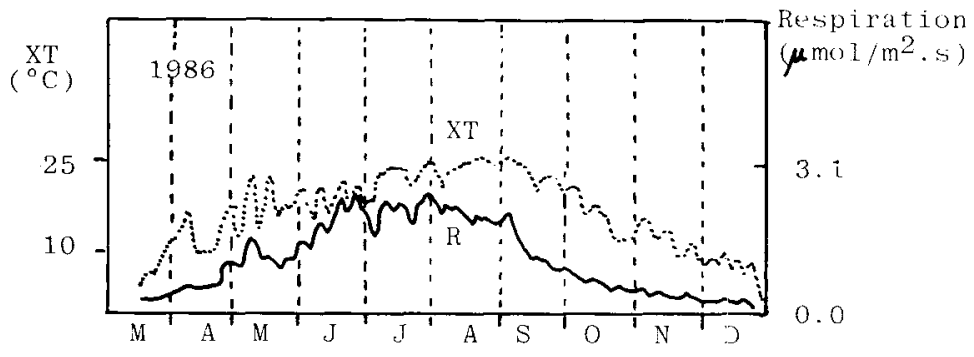

Fig. 1. Seasonal fluctuations of respiration rates $(R)$ and xylem temperature $(X T)$. 


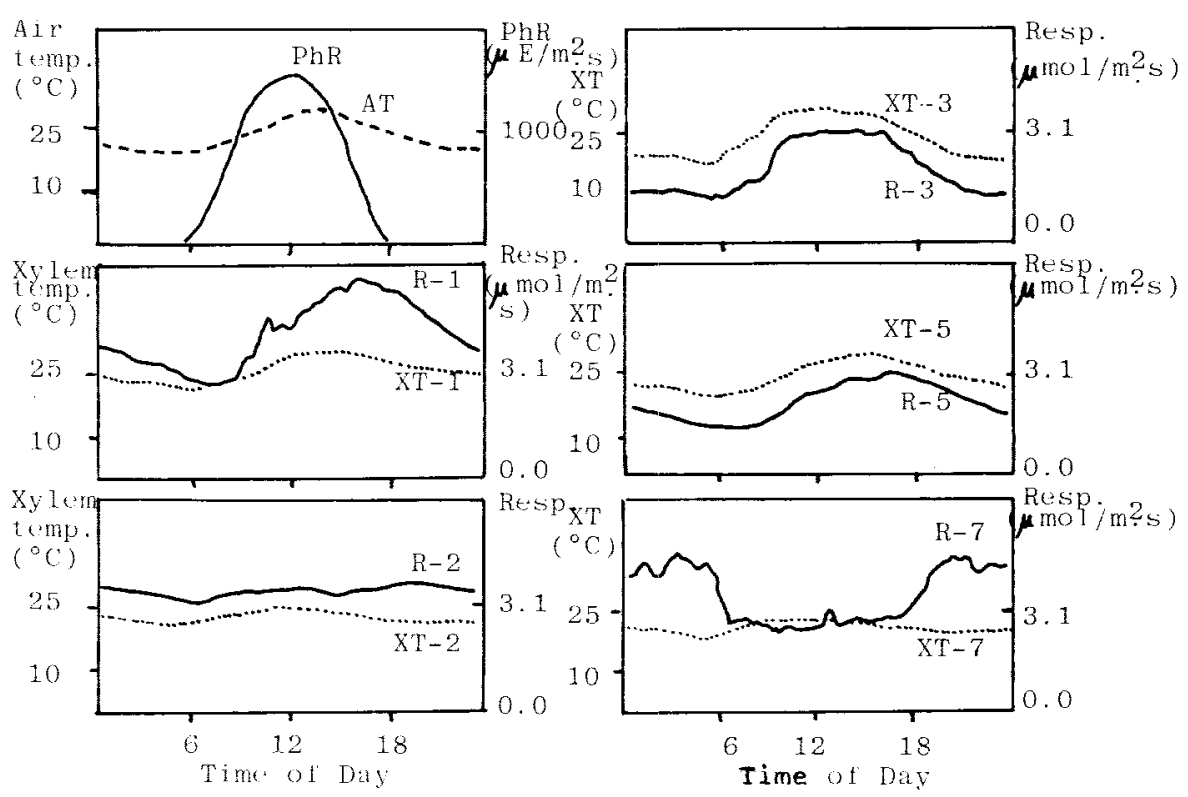

Fig. 2. Diurnal fluctuations of stem respiration (bold line) $\left(\mu \mathrm{mol} / \mathrm{m}^{2} \cdot \mathrm{s}\right)$ together with photosynthetically active radiation $(-)$, air $(\cdots)$ and xylem $(\cdots)$ temperatures.

was not as remarkable as it was on clear days in summer. Negisi studied the daytime depression in bark respiration in young Pinus densiflora trees (1975) and showed that the daytime depression in bark respiration was obscured after shading, defoliation or cutting of the stem at the base level. His results suggest that the water status of trees is an important factor relating to the daytime depression of bark respiration of the stem at the stem base.

\section{References}

Havranek W.M. (1985) Gas exchange and dry matter allocation in larch at the alpine timberline on Mount Patscherkofel. Proc. 3rd IUFRO Workshop P 1.07-00 1984. Eidg. Anst. Forstl. Versuchswes. Ber. 270, 135-142

Johansson N. (1933) The relationship between the tree stem's respiration and its growth. Sven. Skogsvärdsfoeren. Tidskr. 10, 53-134

Kakubari Y. (1988) Diurnal and seasonal fluctuations in the bark respiration of standing Fagus sylvatica trees at Solling, West Germany. J. Jpn. For. Soc. 70, 64-70

Linder S. \& Troeng E. (1981) The seasonal variation in stem and coarse root respiration of a 20-year-old Scots pine (Pinus sylvestris L.). In : Radial Growth in Trees. (Tranquillini W., ed.), Mitt. Forstt. Bundes-Versuchsanst. Wien 142, 125-139

Negisi K. (1975) Diurnal fluctuation of $\mathrm{CO}_{2}$ release from the stem bark of young Pinus densiflora trees. J. Jpn. For. Soc. 57, 375-383 